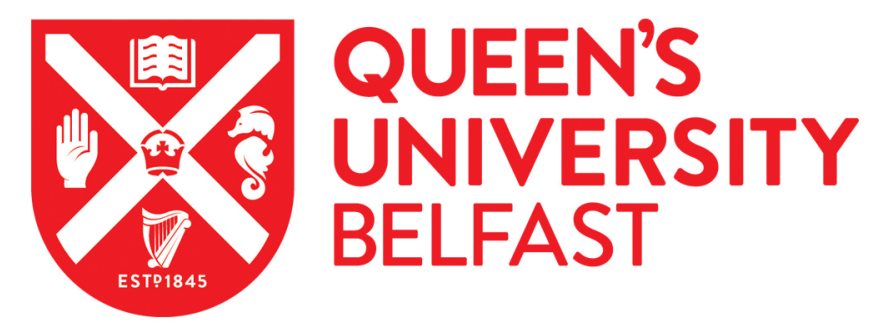

\title{
Explaining binge drinking among adolescent males using the Theory of Planned Behaviour
}

Dempster, M., Newell, G., \& Marley, J. (2005). Explaining binge drinking among adolescent males using the Theory of Planned Behaviour. Irish Journal of Psychology, 26, 17-24.

Published in:

Irish Journal of Psychology

Document Version:

Early version, also known as pre-print

Queen's University Belfast - Research Portal:

Link to publication record in Queen's University Belfast Research Portal

\footnotetext{
General rights

Copyright for the publications made accessible via the Queen's University Belfast Research Portal is retained by the author(s) and / or other copyright owners and it is a condition of accessing these publications that users recognise and abide by the legal requirements associated with these rights.
}

Take down policy

The Research Portal is Queen's institutional repository that provides access to Queen's research output. Every effort has been made to ensure that content in the Research Portal does not infringe any person's rights, or applicable UK laws. If you discover content in the Research Portal that you believe breaches copyright or violates any law, please contact openaccess@qub.ac.uk. 
Dempster et al. 1

Running head: EXPLAINING BINGE DRINKING

\title{
EXPLAINING BINGE DRINKING AMONG ADOLESCENT MALES USING THE
}

THEORY OF PLANNED BEHAVIOUR

\author{
Martin Dempster* \\ School of Psychology, Queen's University Belfast \\ Geoff Newell and John Marley \\ School of Dentistry, Queen's University Belfast
}

*Address for correspondence:

Martin Dempster

School of Psychology

Queen's University Belfast

University Road

Belfast

BT7 1NN

Northern Ireland

Telephone: 02890335547

Fax: 02890664144

Email: m.dempster@qub.ac.uk 


\begin{abstract}
Binge drinking among adolescents in Northern Ireland is prevalent and has detrimental effects on public health. Health education interventions, based on valid explanatory models of health behaviour, are required to reduce binge drinking behaviour among adolescents. This paper examines the utility of the Theory of Planned Behaviour in explaining binge drinking behaviour among adolescent males. Using questionnaire responses from 94 adolescent boys attending secondary schools in the Belfast area, logistic regression modelling suggested that the Theory of Planned Behaviour explained $36 \%$ of the variance in self-reported binge drinking behaviour. Attitudes towards binge drinking were the strongest predictor of binge drinking behaviour. Tackling attitudes about binge drinking is a challenge to be considered when designing interventions to reduce binge drinking among this population.
\end{abstract}


Binge drinking is associated with high levels of morbidity (Perreira \& Sloan, 2002) and mortality (Kauhanen, Kaplan, Goldberg, \& Salonen, 1997). Binge drinking is defined by different criteria but the amount of alcohol which can be consumed in one session and be considered non-binge drinking is up to half the recommended maximum weekly consumption (Bennett, Smith, \& Nugent, 1990). For men, the recommended maximum weekly consumption is 21 units of alcohol per week, where one pint of beer/lager/cider equals 2 units and one measure of spirits equals 1.5 units (Health Promotion Agency Northern Ireland, 2001). Consequently, binge drinking for males (in this research) is defined as drinking more than 10 units of alcohol (for example, more than 5 pints of beer) in one session. These recommendations pertain to adults; the repercussions of drinking these amounts are potentially more severe among younger people.

There is widespread public and governmental concern about the level of alcohol consumption among young people in Ireland. The Health Behaviour in School-Aged Children survey, conducted in the Republic of Ireland, revealed that $60 \%$ of adolescents in the 15-16 year age group are current drinkers (Centre for Health Promotion Studies, 1999) and one third of adolescents in this age group reported binge drinking three or more times in the previous month. In Northern Ireland, one recent study shows that $51 \%$ of $15-16$ year old boys had been intoxicated with alcohol within the previous 30 days (Miller \& Plant, 2001). The Health Promotion Agency Northern Ireland (2000) has also reported that over 80\% of both boys and girls had tasted alcohol by the age of 13 , and that $44 \%$ of boys and $40 \%$ of girls were regular drinkers by age 16. In the Republic of Ireland, during the five years 
from 1996 to 2000, the number of teenagers charged or cautioned for intoxication in public places increased by 370\% (Strategic Task Force on Alcohol, 2002).

These statistics are of public concern, not only because of the detrimental effects on health caused by binge drinking but also because there is a common perception that binge drinking is associated with interpersonal violence, especially among younger people. There is evidence to suggest that the consumption of alcohol by the victim is associated with injury (Telfer, Jones, \& Shepherd, 1991), and that the 15-25 year age group has been shown to be the modal group for alcohol-related facial trauma, assaults and for facial injuries occurring in public bars or on the street (Hutchison, Magennis, Shepherd, \& Brown, 1998). Binge drinking is associated with vulnerability to physical assault and so this pattern of drinking behaviour places adolescents in danger of long-term and short-term life-altering physical trauma (Magennis, Shepherd, Hutchison, \& Brown, 1998).

Clearly it is important to develop and introduce effective health education interventions which will reduce binge drinking among adolescents. Therefore, it is important that we can identify valid predictors of binge drinking behaviour and develop models which describe the paths of action of these predictor variables on binge drinking behaviour. The identification of such explanatory models will promote the design of effective interventions. The Theory of Planned Behaviour (TPB; Ajzen, 1988) has been proposed as a suitable model for explaining how psychosocial variables may combine to predict health-related behaviour. 
The TPB is based on the premise that intention is the best single immediate predictor of behaviour and that there are three main factors predicting behavioural intentions: attitude regarding the behaviour, subjective norm (the perception of and commitment to social standards regarding the behaviour's acceptability or appropriateness), and perceived behavioural control (which is also assumed to have a direct impact on behaviour).

Several systematic reviews have provided support for the use of the TPB in the prediction of a range of behaviours and health behaviours in particular (Armitage \& Conner, 2001). A meta-analysis by Godin and Kok (1996) showed that the TPB accounted for $41 \%$ of the variance in behavioural intentions and $34 \%$ of the variance in health-related behaviours; Armitage and Conner (2001) placed these values at 39\% and $27 \%$ respectively.

The TPB has been researched in the context of many health behaviours that have an effect on public health, such as smoking (Godin, Valois, LePage, \& Desharnais, 1992; Norman, Conner, \& Bell, 1999), exercise (Courneya, Plotnikoff, Hotz, \& Birkett, 2001; Hagger, Chatzisarantis, Biddle, \& Orbell, 2001; Smith \& Biddle, 1999) and dietary behaviour (Astrom \& Rise, 2001; Povey, Conner, Sparks, James, \& Shepherd, 2000a; Povey, Conner, Sparks, James, \& Shepherd 2000b). With regard to alcohol consumption among young people, Norman, Bennett, and Lewis (1998) used the TPB to explore the motivational and attitudinal factors underlying binge drinking and found that the TPB accounted for $29 \%$ of the variance in drinking behaviour, with the perceived control factor exerting the greatest effect. Murgraff, McDermott, and Walsh (2001) found that the TPB explained 27\% of the variance in drinking behaviour among females attending a higher education institution and Armitage, Norman, and Conner (2002) demonstrated that the TPB explained 45\% of 
the variance in binge-drinking intentions (defined liberally as getting very drunk at least twice per week) among male and female students. However, the validity of the TPB regarding binge drinking among adolescents, has not previously been investigated. This paper aims to discern the extent to which the TPB is useful in explaining binge drinking behaviour in adolescent males.

Method

Parental and self consent was obtained from 145 male pupils in six secondary level schools in Belfast, Northern Ireland. All pupils were age 15 or 16 years old. Questionnaires were administered to these pupils in a classroom setting at two points in time, approximately 1 month apart.

The questionnaires contained questions about the amount of alcohol consumed during an average night spent drinking, questions tapping into the constructs comprising the TPB: attitude toward the behaviour, subjective norm, perceived behavioural control and behavioural intention. Questions relating to the TPB were developed following the guidance provided by Ajzen (2002a) and were based on the questions devised by Murgraff, McDermott, and Walsh (2001). Attitudes were assessed via six semantic differential scales (Cronbach's $\alpha=0.77$ ): “For you personally, drinking less than 5 pints, or 7 shorts, or 7 bottles in a session would be..." (for example, unpleasant-pleasant, unsatisfactory-satisfactory). Subjective norm was measured using three items (Cronbach's $\alpha=0.65$ ), for example: "If the people who are important to me approved of me drinking, they would like me to drink less than 5 pints or 7 shorts or 7 bottles in a session". Three items (for example: "Whether or not I drink less than 5 pints or 7 shorts or 7 bottles in a session is largely 
controlled by myself") tapped into the construct of perceived behavioural control (Cronbach's $\alpha=0.44$ ). Behavioural intention was also assessed using three items (Cronbach's $\alpha=0.83$ ), for example: “After I have drunk 5 pints or 7 shorts or 7 bottles in 1 session, if I was offered more alcohol I would refuse it".

Of the 145 participants initially recruited in the study, about 5\% (7/145) did not complete the questions about their drinking behaviour; about $75 \%$ of the remaining participants (104/138) reported drinking alcohol and only these participants were asked to complete the questions pertaining to the TPB. A total of $88 \%(91 / 104)$ of the participants who reported drinking alcohol completed the questionnaire fully at time $1 ; 75$ of these participants completed the questionnaire at time 2 .

\section{Results}

For the remaining 94 participants, the reported amount of alcohol consumed in one night was positively skewed, with median (and mode) of 12 units (inter-quartile range $=8.6$ units). About 67\% (61/91) of drinkers were binge drinkers. Descriptive statistics for the components of the TPB are presented in Table 1.

A logistic regression model (using the enter method) examined the relationship between the three predictor variables (attitude, subjective norm and perceived behavioural control) and binge drinking behaviour. The results presented here are for the final regression model, after the examination of residual scores and the removal of 3 outliers (see Table 2). The $R^{2}$ values were calculated using the method suggested by Hosmer and Lemeshow (1989). The model increased the 
classification accuracy to $73.6 \%$, with accurate prediction of binge drinkers at almost $84 \%$.

The chi-squared result suggests that the predictor variables add significantly to the explanation of binge drinking, however the statistics for each variable show that the attitude component is the strongest (and only statistically significant) predictor of binge drinking. In summary, it appears that the odds of being a binge drinker increase by approximately 1.5 times for every one unit decrease on the attitude scale.

The above regression model does not include the behavioural intention component of the TPB. In order to examine this component, binge drinking behaviour at the second point in time was assessed and regressed on intention (in block 1) and the remaining three components of the TPB (in block 2) in a hierarchical regression model. The results are presented in Table 3, which shows that intention explains almost $12 \%$ of the variance in behaviour (as shown by the $\mathrm{R}^{2}$ value), but most of this is accounted for by the attitude component. In fact, in a standard linear regression model (see Tables 4 and 5), it becomes apparent that attitude is the only significant predictor of intention (in a model explaining up to $36 \%$ of the variance, as shown by the $\mathrm{R}^{2}$ value), thereby emphasising the importance of this component of the model in the context of binge drinking.

\section{Discussion}

The results suggest that the components of the TPB (attitude, subjective norm and perceived behavioural control) explain up to approximately $36 \%$ of the variance in behavioural intention and approximately $36 \%$ of the variance in binge drinking 
behaviour. This figure is similar to the figure proposed by Godin and Kok (1996) for a range of health behaviours and is higher than the figures proposed by Murgraff, McDermott, and Walsh (2001) and Norman, Bennett, and Lewis (1998) for binge drinking behaviour among adults. However, only the attitude component contributed significantly to the explanation of binge drinking behaviour at the same point in time or the prediction of binge drinking behaviour one month later. In fact, within this model the attitude component appears to have an overriding influence on binge drinking behaviour.

The failure of the perceived behavioural control component to explain a significant proportion of the variance in behaviour or behavioural intentions is surprising given that previous research has found strong relationships between perceived behavioural control and consumption of alcohol (Norman, Bennett, \& Lewis, 1998) among adults. However, difficulty with the perceived behavioural control-behaviour link has been found previously. Recent work concerning the perceived behavioural control component suggests that it should be conceptualised as two components: self-efficacy and controllability (Ajzen, 2002b), although there is still some controversy about the exact nature of the relationship between these two dimensions and issues concerning the measurement of perceived behavioural control are yet to be resolved (Rhodes \& Courneya, 2003). Given that the operational definition of perceived behavioural control in the present study did not address the possible separation of these two components, this may explain, to some extent, the poor predictive power of the concept and the poor internal consistency of the dimension in the present study. Another explanation for this finding is that perceived behavioural control is simply not an important predictor (relative to attitudes) among this population of adolescent males. We turn our attentions to the attitudes dimension 
shortly. However, it must be further emphasised that the measurement of perceived behavioural control in this study suffers from a large amount of measurement error (as evidenced by the lack of consistency of the items) and so conclusions about the relationship between perceived behavioural control and binge drinking cannot be drawn from this study alone.

The failure of subjective norm to explain a significant proportion of the variance in behaviour or behavioural intentions is not surprising as previous research has often shown that the subjective norm component has a weaker relationship with behaviour than the attitude component (Armitage \& Conner, 2001; Terry, Hogg, \& White 1999). A recent study on binge drinking has attempted to address this inadequacy of the TPB model by utilising social identity theory/self-categorisation theory and has demonstrated that perceived norms of a relevant reference group predict intentions to binge drink for individuals who strongly identify with the reference group (Johnston \& White, 2003). This appears to be a more useful operationalisation of the subjective norm concept within the context of this behaviour and such a framework may help to raise the internal consistency of the items designed to assess this construct.

The importance of the attitude component in this setting is clear - having generally positive thoughts about the activity of binge drinking is the main determinant of binge drinking behaviour among the adolescent males participating in the study. A review of research on drinking behaviour among young people states that binge drinking is not considered risky by young people and any adverse consequences are seen to be acceptable (Murgraff, Parrott, \& Bennett, 1999). This finding suggests a prevailing unrealistic optimism (Weinstein, 1987) about the effects of binge drinking among young people (undoubtedly reinforced by the behaviour of 
adults) and may explain the attitude-behaviour link in the present study. The implication is that any interventions designed to reduce binge drinking among adolescents must begin by tackling this unrealistic optimism and demonstrating the adverse consequences to young people in a way which will emphasise the immediate effects of binge drinking in addition to the long term effects normally presented. Effects such as liver damage, frequently cited as one of the adverse consequences of binge drinking, have no immediacy for adolescents and they often perceive this outcome to be something they can avoid by changing their behaviour at some point in the future. Interventions must encourage adolescents to perceive binge drinking as a clear and present danger, by presenting information such as that cited earlier regarding the association between binge drinking and facial injury (Magennis, Shepherd, Hutchison, \& Brown, 1998).

Undoubtedly binge drinking behaviour is reinforced by the behaviour modelled by significant others and the perceived culture in Ireland is one which not only accepts binge drinking, but actively encourages it. Consequently, interventions targeting individual behaviour are unlikely to be successful without the accompaniment of other environmental influences targeted at society (Edwards et al., 1994, p.180). The challenge for health educators is an onerous one - develop a programme which: is applicable to adolescents; can be delivered in a classroom setting; raises awareness of the risks associated with binge drinking in a tangible, potent, and ethical manner; and has a lasting effect on behaviour. Addressing attitudes about binge drinking will be a small but important first step in this process. 
Dempster et al. 12

Acknowledgements

This work was supported by funding from the British Academy. 


\section{References}

Ajzen, I. (1988). Attitudes, personality and behavior. Milton Keynes: Open University Press.

Ajzen, I. (2002a). Constructing a TPB questionnaire: Conceptual and methodological considerations. Retrieved from http://wwwunix.oit.umass.edu/ ajzen/

Ajzen, I. (2002b). Perceived behavioural control, self-efficacy, locus of control, and the theory of planned behaviour. Journal of Applied Social Psychology, 32, $665-683$.

Armitage, C. J., \& Conner, M. (2001). Efficacy of the theory of planned behaviour: A meta-analytic review. British Journal of Social Psychology, 40, 471-499.

Armitage, C. J., Norman, P., \& Conner, M. (2002). Can the Theory of Planned Behaviour mediate the effects of age, gender and multidimensional health locus of control? British Journal of Health Psychology, 7, 299-316.

Astrom, A. N., \& Rise, J. (2001). Young adults' intention to eat healthy food: Extending the theory of planned behaviour. Psychology and Health, 16, 223237.

Bennett, P., Smith, C., \& Nugent, Z. (1990). Binge drinking in Wales: Good Health Wales Briefing Report 2. Cardiff: Health Promotion Authority for Wales. Centre For Health Promotion Studies. (1999). The national health and lifestyle surveys (SLÁN and HBSC). Galway: NUI Galway.

Courneya, K. S., Plotnikoff, R. C., Hotz, S. B., \& Birkett, N. J. (2001). Predicting exercise stage transitions over two consecutive 6-month periods: A test of the 
theory of planned behaviour in a population-based sample. British Journal of Health Psychology, 6, 135-150.

Edwards, G., Anderson, P., Babor, T. F., Casswell, S., Ferrence, R., Giesbrecht, N., et al. (1994). Alcohol policy and the public good. Oxford: Oxford University Press.

Godin, G., \& Kok, G. (1996). The theory of planned behavior: A review of its applications to health-related behaviors. American Journal of Health Promotion, 11, 87-98.

Godin, G., Valois, P., LePage, L., \& Desharnais, R. (1992). Predictors of smoking behaviour: An application of Ajzen's theory of planned behaviour. British Journal of Addiction, 87, 1335-1343.

Hagger, M. S., Chatzisarantis, N., Biddle, S. J. H., \& Orbell, S. (2001). Antecedents of children's physical activity intentions and behaviour: Predictive validity and longitudinal effects. Psychology and Health, 16, 391-407.

Health Promotion Agency Northern Ireland. (2000). Health behaviour of school children in Northern Ireland: A report on the 1997/1998 survey. Belfast: Health Promotion Agency Northern Ireland.

Health Promotion Agency Northern Ireland. (2001). Focus on Alcohol: A Guide to Drinking and Health. Belfast: Health Promotion Agency Northern Ireland.

Hosmer, D. W., \& Lemeshow, S. (1989). Applied logistic regression. New York: Wiley.

Hutchison, I., Magennis, P., Shepherd, J., \& Brown, A. (1998). The BAOMS United Kingdom Survey of Facial Injuries Part 1: Aetiology and the association with alcohol consumption. British Journal of Oral Maxillofacial Surgery, 36, 4-14. 
Johnston, K. L., \& White, K. M. (2003). Binge-drinking: A test of the role of group norms in the theory of planned behaviour. Psychology and Health, 18, 63-77.

Kauhanen, J., Kaplan, G. A., Goldberg, D. E., \& Salonen, J. T. (1997). Beer binging and mortality: Results from the Kuiopo ischaemic heart disease risk factor study, a prospective population based study. British Medical Journal, 315, 846-851.

Magennis, P., Shepherd, J., Hutchison, I., \& Brown, A. (1998). Trends in facial injury. British Medical Journal, 316, 325-326.

Miller, P., \& Plant, M. (2001). Drinking, smoking and illicit drug use among 15 and 16 year old school students in Northern Ireland. Belfast: Department of Health, Social Services and Public Safety, Northern Ireland.

Murgraff, V., McDermott, M. R., \& Walsh, J. (2001). Exploring attitude and belief correlates of adhering to the new guidelines for low-risk single-occasion drinking: an application of the theory of planned behaviour. Alcohol and Alcoholism, 36, 135-140.

Murgraff, V., Parrott, A., \& Bennett, P. (1999). Risky single-occasion drinking amongst young people - definition, correlates, policy, and intervention: A broad overview of research findings. Alcohol and Alcoholism, 34, 3-14.

Norman, P., Bennett, P., \& Lewis, H. (1998). Understanding binge drinking among young people: An application of the theory of planned behaviour. Health Education Research, 13, 163-169.

Norman, P., Conner, M., \& Bell, R. (1999). The theory of planned behaviour and smoking cessation. Health Psychology, 18, 89-94. 
Perreira, K. M., \& Sloan, F. A. (2002). Excess alcohol consumption and health outcomes: A 6-year follow-up of men over age 50 from the health and retirement study. Addiction, 97, 301-310.

Povey, R., Conner, M., Sparks, P., James, R., \& Shepherd, R. (2000a). Application of the theory of planned behaviour to two dietary behaviours: Roles of perceived control and self-efficacy. British Journal of Health Psychology, 5, 121-139.

Povey, R., Conner, M., Sparks, P., James, R., \& Shepherd, R. (2000b). The theory of planned behaviour and healthy eating: Examining additive and moderating effects of social influence variables. Psychology and Health, 14, 991-1006.

Rhodes, R. E., \& Courneya, K. S. (2003). Self-efficacy, controllability and intention in the theory of planned behaviour: Measurement redundancy or causal independence? Psychology and Health, 18, 79-91.

Smith, R. A., \& Biddle, S. J. H. (1999). Attitudes and exercise adherence: Test of the theories of reasoned action and planned behaviour. Journal of Sports Sciences, 17, 269-281.

Strategic Task Force on Alcohol. (2002). Interim report. Dublin: Department of Health and Children.

Telfer, M. R., Jones, G. M., \& Shepherd, J. P. (1991). Trends in the aetiology of maxillofacial fractures in the UK. British Journal of Oral Maxillofacial Surgery, 29, 250-255.

Terry, D. J., Hogg, M. A., \& White, K. M. (1999). The theory of planned behaviour: Self-identity, social identity and group norms. British Journal of Social Psychology, 28, 225-244. 
Weinstein, N.D. (1987). Unrealistic optimism about susceptibility to health problems:

Conclusions from a community-wide sample. Journal of Behavioral Medicine, 10, $481-500$ 
Table 1

Descriptive Statistics for the Theory of Planned Behaviour Components

\begin{tabular}{lcccc}
\hline & Mean & Std. Dev. & Range & Possible Range \\
\hline Attitude & 31.20 & 7.15 & 9 to 42 & 6 to 42 \\
Subjective Norm & 15.99 & 5.85 & 3 to 21 & 3 to 21 \\
Perceived Behavioural & 17.79 & 3.44 & 8 to 21 & 3 to 21 \\
Control & & & & \\
Behavioural Intention & 13.96 & 5.20 & 3 to 21 & 3 to 21 \\
(Time 1) & & & & \\
Behavioural Intention & 12.30 & 5.04 & 3 to 21 & 3 to 21 \\
(Time 2) & & & & \\
\hline
\end{tabular}


Table 2

Binary Logistic Regression Model with Not Binge Drinking at Time 1 as the Outcome

\begin{tabular}{|c|c|c|c|c|c|}
\hline & $\begin{array}{l}\text { B } \\
\text { (unstandardised } \\
\text { coefficient) }\end{array}$ & $\begin{array}{l}\text { Odds } \\
\text { Ratio }\end{array}$ & Wald & $p$ & $95 \% \mathrm{Cl}$ \\
\hline Constant & 9.50 & 13335.42 & 12.61 & $<.001$ & \\
\hline Attitude & 0.36 & 1.44 & 16.89 & $<.001$ & $1.21-1.71$ \\
\hline Subjective Norm & 0.08 & 1.08 & 2.53 & .11 & $0.98-1.19$ \\
\hline $\begin{array}{l}\text { Perceived Behavioural } \\
\text { Control }\end{array}$ & 0.12 & 1.13 & 1.14 & .29 & $0.91-1.40$ \\
\hline
\end{tabular}

Note: $R^{2}=0.36 ; \chi^{2} 3 ; n=91=40.96, p<.001$ 
Table 3

Binary Logistic Regression Model with Not Binge Drinking at Time 2 as the Outcome

\begin{tabular}{|c|c|c|c|c|c|}
\hline & $\begin{array}{l}\text { B } \\
\text { (unstandardised } \\
\text { coefficient) }\end{array}$ & $\begin{array}{l}\text { Odds } \\
\text { Ratio }\end{array}$ & Wald & $p$ & $95 \% \mathrm{Cl}$ \\
\hline \multicolumn{6}{|l|}{ Model $1^{\mathrm{a}}$} \\
\hline Constant & 4.31 & 74.75 & 8.57 & .003 & \\
\hline Behavioural Intention & 0.15 & 1.16 & 8.43 & .004 & $1.05-1.29$ \\
\hline Perceived Behavioural & -0.09 & 0.91 & 1.35 & .25 & $0.78-1.06$ \\
\hline \multicolumn{6}{|l|}{ Control } \\
\hline \multicolumn{6}{|l|}{ Model $2^{b}$} \\
\hline Constant & 6.54 & 688.85 & 10.87 & .001 & \\
\hline Behavioural Intention & 0.07 & 1.08 & 1.39 & .24 & $0.95-1.22$ \\
\hline Attitude & 0.16 & 1.17 & 7.93 & .005 & $1.05-1.30$ \\
\hline Subjective Norm & 0.003 & 1.00 & 0.01 & .94 & $0.92-1.09$ \\
\hline Perceived Behavioural & 0.01 & 1.01 & 0.003 & .96 & $0.84-1.21$ \\
\hline Control & & & & & \\
\hline
\end{tabular}

Notes: ${ }^{\mathrm{a}} R^{2}=0.12 ; \chi^{2}{ }_{2 ; n=75}=14.79, p=.001 ;{ }^{b} R^{2}=0.20 ; \chi_{4 ; n=81}^{2}=24.13, p<.001$ 
Dempster et al. 21

Table 4

Linear Regression Model with Behavioural Intention at Time 1 as the Outcome

\begin{tabular}{llllll}
\hline & $\begin{array}{l}B \text { (unstandardised } \\
\text { coefficient) }\end{array}$ & $\begin{array}{l}B \text { (standardised } \\
\text { coefficient) }\end{array}$ & & $p$ & $95 \% \mathrm{Cl}$ \\
& -1.04 & & -0.39 & .70 & $-6.43-4.34$ \\
\hline Constant & 0.44 & 0.60 & 6.08 & $<.001$ & $0.29-0.58$ \\
Attitude & 0.07 & 0.08 & 0.94 & .35 & $-0.08-0.22$ \\
Subjective Norm & 0.01 & 0.01 & 0.10 & .92 & $-0.28-0.31$ \\
Perceived & & & & & \\
Behavioural Control & & & & & \\
\hline
\end{tabular}

Note: $R^{2}=0.36 ; F_{3,87}=17.59, p<.001$ 
Dempster et al. 22

Table 5

Linear Regression Model with Behavioural Intention at Time 2 as the Outcome

\begin{tabular}{llllll}
\hline & $\begin{array}{l}B \text { (unstandardised } \\
\text { coefficient) }\end{array}$ & $\begin{array}{l}B \text { (standardised } \\
\text { coefficient) }\end{array}$ & & $p$ & $95 \% \mathrm{Cl}$ \\
& -0.21 & & -0.22 & .83 & $-2.13-1.71$ \\
\hline Constant & 0.12 & 0.51 & 4.29 & $<.001$ & $0.06-0.17$ \\
Attitude & 0.04 & 0.14 & 1.38 & .17 & $-0.02-0.10$ \\
Subjective Norm & 0.004 & 0.01 & 0.07 & .95 & $-0.11-0.12$ \\
Perceived & & & & & \\
Behavioural Control & & & & & \\
\hline
\end{tabular}

Note: $R^{2}=0.31 ; F_{3,71}=10.50, p<.001$ 